\title{
《Research Note» \\ Influence of Trypsin-Digested Wheat Gluten Peptides with Different Molecular Size on Intestinal Absorption of Amino Acids in Chickens
}

\author{
Ken R. Ito ${ }^{1}$ and Kazumi Kita ${ }^{1,2}$ \\ ${ }^{1}$ The United Graduate School of Agricultural Sciences, Iwate University, Morioka, Iwate 020-8550, Japan \\ ${ }^{2}$ Faculty of Agriculture, Iwate University, Morioka, Iwate 020-8550, Japan
}

\begin{abstract}
Although a lot of food-derived peptides have been applied for medical use and therapeutic nutrition, the function of feed-derived peptides on nutritional physiology in chickens has not been clarified so far. Our previous study revealed that wheat gluten digested by trypsin could enhance the absorption of amino acids from small intestine. In the present study, we studied the influence of trypsin-digested wheat gluten peptides with different molecular weight (MW) on the intestinal absorption of amino acids in chickens. Wheat gluten was digested by trypsin and fractionated by using the ultrafiltration membrane. Wheat gluten peptides were divided into 3 fractions with different MW; MW more than 10,000, MW 3,000-10,000 and MW less than 3,000. Phosphate buffered saline and whole wheat gluten digesta were used as negative and positive controls, respectively. All of wheat gluten peptides were mixed with $2.5 \mathrm{M}$ glucose- $10 \mathrm{mM}$ amino acid solution and administrated into the crop with a stomach tube. At $20 \mathrm{~min}$ after oral administration, blood samples were taken from mesenteric vein. Plasma amino acid concentration was determined using an automatic amino acid analyzer. The peptide fraction with MW more than 10,000 increased the intestinal absorption of phenylalanine and proline. The peptide fraction with MW 3,000-10,000 increased the intestinal absorption of proline. These results suggest that wheat gluten peptide with high MW might have the potency to enhance the absorption of aromatic amino acids from small intestine of young chickens.
\end{abstract}

Key words: absorption, amino acid, peptide, small intestine, trypsin digestion, wheat gluten

$$
\text { J. Poult. Sci., 53: 40-42, } 2016
$$

\section{Introduction}

Recently, a lot of functional peptides derived from digested foods have been applied for medical use and therapeutic nutrition (Hartmann and Meisei, 2007). In the poultry industry, however, the function of feed-derived peptides has not been studied yet. Previously, we examined the influence of trypsin-digested grain proteins on intestinal absorption of glucose and amino acids in chickens. The digesta of soybean protein and corn zein did not affect the intestinal absorption of glucose and amino acid. On the other hand, the digesta of wheat gluten increased the absorption of asparagine, glutamine, phenylalanine and proline from small intestine (Ito and Kita, 2013). In this report, however, functional peptides in trypsin-digested wheat gluten have not been characterized yet. In the present study, therefore, we fractionated trypsin-digested wheat gluten peptides with different molecular weight and examined the influence of these peptides on the intestinal absorption of amino acids in

Received: January 4, 2015, Accepted: July 2, 2015

Released Online Advance Publication: August 25, 2015

Correspondence: Dr. K. Kita, Faculty of Agriculture, Iwate University,

Morioka, Iwate 020-8550, Japan. (E-mail: kitak@iwate-u.ac.jp) chickens.

\section{Materials and Methods}

\section{Preparation of Trypsin-Digested Wheat Gluten Peptides}

Approximate $1 \mathrm{~g}$ of wheat gluten was accurately weighted and added $20 \mathrm{~mL}$ of $0.5 \%$ trypsin solution. After shaken at $37^{\circ} \mathrm{C}$ for $20 \mathrm{~h}$ to digest wheat gluten thoroughly, samples were boiled for $20 \mathrm{~min}$ to inactive trypsin and chilled for 10 min in cold water. After passed through a $0.22 \mu \mathrm{m}$ membrane filter, they were frozen and stored at $-20^{\circ} \mathrm{C}$.

At first, wheat gluten digesta was fractionated by using the ultrafiltration membrane unit $\left(\right.$ Micron ${ }^{\circledR}$ Ultracel YM-10 Regenerated Cellulose 10,000MWCO, Millipore Co., Ltd., Billerica MA, USA). The fraction remained in the membrane unit was collected and used as the fraction with MW more than 10,000 . Subsequently, the filtrate was fractionated with another ultrafiltration membrane unit $\left(\right.$ Amicon $^{\circledR}$ Ultra-0.5, Ultrace ${ }^{\circledR}-3 \mathrm{~K}$ Membrane, Regenerated Cellulose 3,000 MWCO, Millipore Co., Ltd.). The fraction remained in the membrane unit was collected and used as the fraction with MW 3,000-10,000. The filtrate was used as fraction with MW less than 3,000. 


\section{Oral Administration of Trypsin-Digested Wheat Gluten Peptides}

Newly hatched single comb White Leghorn male chicks were purchased from a local hatchery (Koiwai Farm Co., Ltd, Shizukuishi, Iwate, Japan). They were allowed free access to water and a commercial chick mash (Toyohashi Feed Mills Co. Ltd., Toyohashi, Aichi, Japan) for 3 weeks. All birds were raised in a chick brooder (Showa Franki Co., Ltd., Ina, Saitama, Japan). The temperature was kept at $29^{\circ} \mathrm{C}$ for the first week and then lowered progressively afterward. At 3 weeks of age, 35 chickens were selected and used for the following experiment.

Five treatments $(n=7)$ were set as follows; 1) Dulbecco's phosphate-buffered saline (DPBS) and glucose-amino acid solution (negative control), 2) whole wheat gluten digesta and glucose-amino acid solution (positive control), 3) the fraction with MW more than 10,000 and glucose-amino acid solution, 4) the fraction with MW 3,000-10,000 and glucoseamino acid solution, 5) the fraction with MW less than 3,000 and glucose-amino acid solution. The glucose-amino acid solution included $2.5 \mathrm{M}$ glucose and $10 \mathrm{mM}$ amino acids (Ito and Kita, 2013) and was mixed with fractions at the ratio of $1: 1$. After fasting for $16 \mathrm{~h}, 1 \mathrm{~mL}$ of mixture solution was orally administrated into the crop of chickens using a stomach tube. At $20 \mathrm{~min}$ after oral administration, blood samples were taken from mesenteric vein (Ito and Kita, 2013).

Blood samples were placed on ice and then centrifuged at $4^{\circ} \mathrm{C}, 10,000 \times \mathrm{g}$ for $20 \mathrm{~min}$. After collecting plasma, it was a)

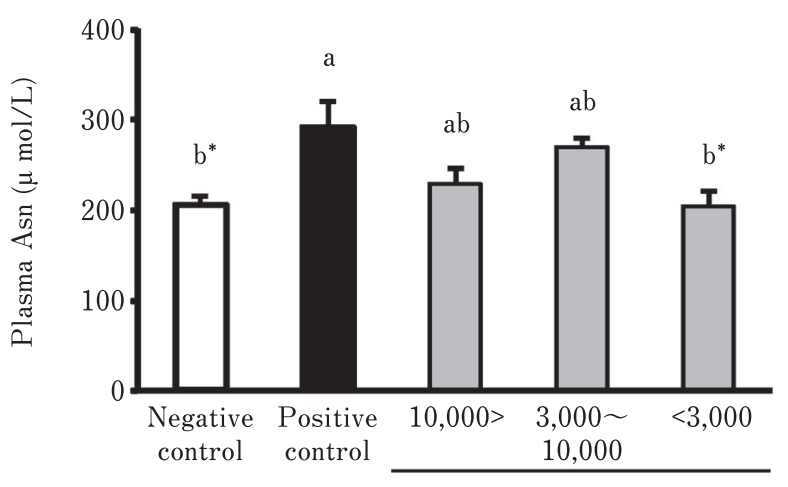

Molecular weight

c)

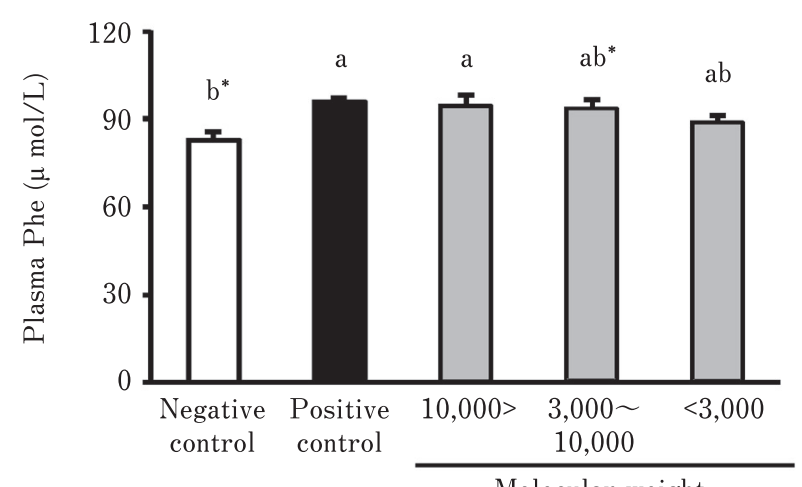

b)

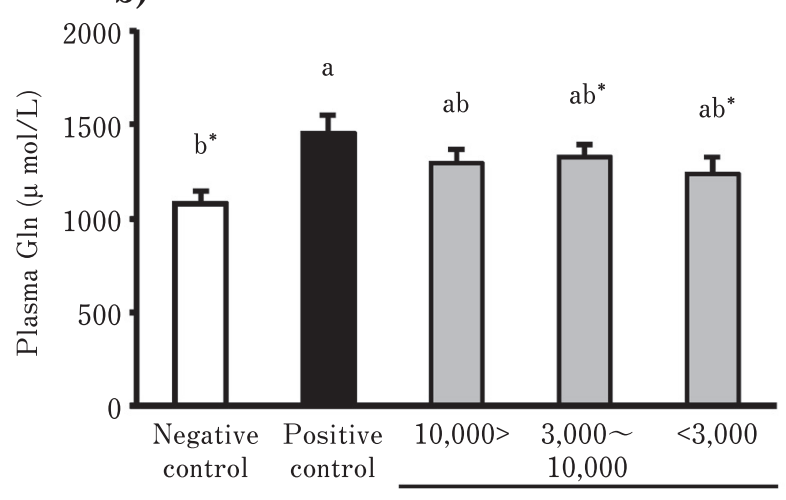

Molecular weight

d)

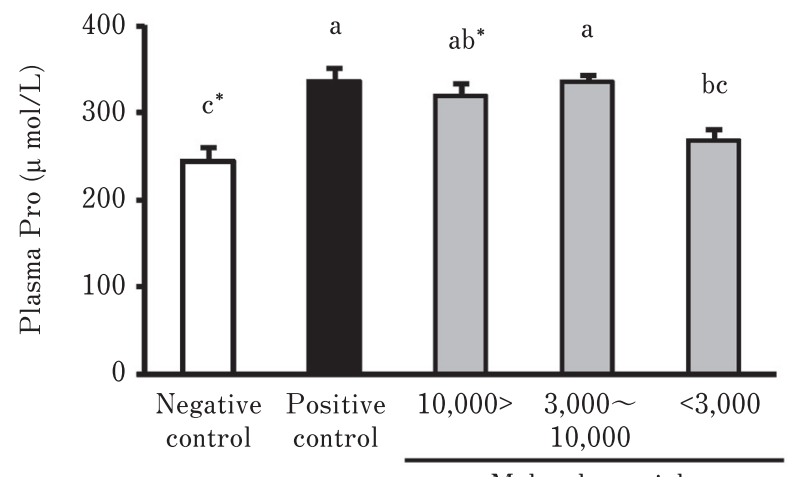

Molecular weight

Fig. 1. Plasma amino acid concentrations in young chickens orally administrated with the mixture of trypsin-digested wheat gluten peptides and glucose-amino acid solution. Chickens in the negative control were given only the mixture of $1.25 \mathrm{M}$-glucose-5 mM amino acids solution. The positive control were given the mixture of whole gluten digesta and glucose-amino acid solution. At 20 minutes after administration, blood samples were taken from the mesenteric vein. Amino acid concentrations were determined by using an automatic amino acid analyzer. a) Plasma asparagine concentrations when fractions were administrated. b) Plasma glutamine concentrations when fractions were administrated. c) Plasma phenylalanine concentrations when fractions were administrated. d) Plasma proline concentrations when fractions were administrated. ${ }^{\mathrm{a} \sim \mathrm{c}}$ Means with different superscript letters are significantly different $(P<0.05)$. Values were means \pm SE. $n=7$. * One missing value. 
frozen and stored at $-20^{\circ} \mathrm{C}$ until analyses. Before measuring amino acid concentrations, plasma samples were mixed with an equal volume of $3 \%$ sulfosalicylic acid and stored at $4^{\circ} \mathrm{C}$ for $1 \mathrm{~h}$ for deproteinization. Then, the samples were centrifuged at $4^{\circ} \mathrm{C}, 10,000 \times \mathrm{g}$ for $10 \mathrm{~min}$. The supernatant was taken and passed through a $0.22 \mu \mathrm{m}$ membrane filter. Deproteinized samples were stored at $4^{\circ} \mathrm{C}$ overnight. After membrane filtration was repeated, samples were set on an automatic amino acid analyzer (All Automatic Amino Acid Analyzer, JEOL Ltd., Tokyo, Japan).

\section{Statistical Analysis}

Results are expressed as means \pm SE. Statistical analysis of data was performed by one-way ANOVA and Tukey's HSD test for multiple comparisons $(P<0.05)$ using the General Linear Model Procedures of SAS (SAS version 9.4) (SAS Institute, 2012).

\section{Results}

Plasma concentrations of asparagine, glutamine, phenylalanine and proline of chickens given whole wheat gluten digesta group were significantly higher than that of the negative control group (Fig. 1). However, all of fractionated wheat gluten digesta did not affect plasma levels of asparagine and glutamine (Fig. 1a and 1b). Plasma concentration of phenylalanine in chickens given the fraction with $\mathrm{MW}$ more than 10,000 was equal to the positive control group (Fig. 1c). When chickens were given the fractions with MW more than 10,000 and MW 3,000-10,000, plasma proline concentration was equal to the positive control group (Fig. 1d).

\section{Discussion}

As shown in Figs $1 \mathrm{a}-1 \mathrm{~d}$, when wheat gluten digesta was orally administrated to chickens, it stimulated the absorption of asparagin, glutamine, phenylalanine and proline from small intestine. This result is in good agreement with our previous report (Ito and Kita, 2013). However, when wheat gluten digesta fractionated by using an ultrafiltration membrane was orally administrated to chickens, any fractions did not affect the absorption of asparagine and glutamine from small intestine (Figs 1a and 1b). Aa glutamine is absorbed by the common amino acid transporter which is System N transporter (Mackenzie and Erickson, 2003), our results suggested that individual fraction did not affect the System $\mathrm{N}$ transporter, especially when fraction with MW less than 3,000 was administrated. In other words, combination of fractions could stimulate the absorption of glutamine and asparagine by System $\mathrm{N}$ transporter. On the other hand, the fraction with MW more than 10,000 stimulated the absorp- tion of phenylalanine from small intestine, and the fraction with MW more than 3,000 stimulated the absorption of proline from small intestine (Figs 1c and 1d). It has been well known that amino acids are transported by specific membrane protein called by amino acid transporters from the intestinal lumen into the blood circulation. As System PHE and/or System $\mathrm{T}$ transporters can transport phenylalanine (Hyde et al., 2003), the fraction of wheat gluten digesta with MW more than 10,000 would have potency to accelerate the rate of phenylalanine transport by System PHE and/or System $\mathrm{T}$ transporters. Additionally, System IMUNO transporter is able to transport proline (Bröer, 2008), and the fractions of wheat gluten digesta with MW more than 3,000 might simulate the rate of proline transport by System IMUNO transporter. Recently, Reitsma et al. (2014) reported that M cell on Peyer's patch cells could recognize feed-derived proteins or peptides. In addition, McDole et al. (2012) reported that goblet cells could transport the peptide from lumen to dendritic cells in mucosal layer. However, the mechanism recognizing feed-derived proteins and peptides which can accelerate the rate of amino acid absorption is still unknown.

We need to investigate the relation of wheat glutenderived high molecular peptides to the transport velocity of amino acids in the nearly future.

\section{References}

Bröer S. Apical transporters for neutral amino acids: physiology and pathophysiology. Physiology, 23: 95-103. 2008.

Hartmann R and Meisel H. Food-derived peptides with biological activity: from research to food applications. Current Opinion in Biotechnology, 18: 163-169. 2007.

Hyde R, Taylor MP and Hundal SH. Amino acid transporters: roles in amino acid sensing and signaling in animal cells. Biochemical Journal, 373: 1-18. 2003.

Ito RK and Kita K. Grain proteins digested by trypsin modify plasma amino acid concentration in chickens. Journal of Poultry Science, 50: 340-345. 2013.

Mackenzie B and Erickson JD. Sodium-coupled neutral amino acid (System N/A) transporters of the SLC38 gene family. Pflügers Archiv: European Journal of Physiology, 447: 784-795. 2004.

McDole JR, Wheeler LW, McDonald KG, Wang B, Konjufca V, Knoop AK, Nweberry DR and Miller JM. Goblet cells deliver luminal antigen to $\mathrm{CD} 103^{+}$dendritic cells in the small intestine. Nature, 483: 345-349. 2012.

Reitsma M, Westerhout J, Wichers HJ, Wortelboer HM and Verhoeckx KC. Protein transport across the small intestine in food allergy. Molecular Nutrition and Food Research, 58: 194-205. 2014.

SAS Institute. SAS/STAT ${ }^{\circledR} 13.1$ User's Guide. SAS Institute. North Carolina. 2012. 